\title{
NOTAS SOBRE A RELAÇÃO LÚDICA DA CRIANÇA COM A LINGGUA: A QUESTÃO D̉O RECALQUE DOS SONS
}

\author{
NOTES ON THE CHILD'S PLAYFUL RELATIONSHIP WITH \\ LANGUAGE: THE QUESTION OF SOUND REPRESSION
}

Glória Maria Monteiro de CARVALHO'

Resumo: Este artigo consiste numa tentativa de focalizar os jogos sonoros infantis, em um momento inicial da constituição do falante. Assumimos a proposta psicanalítica de que, para essa constituição, é de capital importância a relação lúdica da criança com os sons da língua, relação que se manifesta por meio de uma diversidade de jogos sonoros. Por sua vez, de acordo com tal proposta, o infans deve esquecer/ recalcar essas manifestações sonoras, para que se torne falante. Nessa perspectiva, colocamos em discussão alguns jogos sonoros de uma criança, à luz da concepção de recalque do som (POMMIER, 2017).

Palavras-chave: Aquisição de linguagem. Jogos sonoros. Significante. Recalque.
Abstract: This article is an attempt to focus on children's sound plays, at an early stage of the speaker's constitution. We assume the psychoanalytic proposition that, for this constitution, the playful relationship of the child with the sounds of the language is of prime importance, and this relationship is disclosed through a diversity of sound plays. In turn, according to such a proposal, the infants must forget / repress these sound manifestations, so that he or she becomes a speaker. In this perspective, we put into question some children's sound plays, in the light of the conception of sound repression (POMMIER, 2017).

Keywords: Language Acquisition. Sound Plays. Signifier. Repression.

1 Carvalho. UNICAP. E-mail: gloria.carvalho@unicap.br. ORCID ID: http://orcid.org/0000-0003-0595-1764. 
- | Notas sobre a relação lúdica da criança com a língua: a questão do recalque dos sons

\section{Introdução ${ }^{2}$}

Pretendemos, neste artigo, focalizar a relação lúdica da criança com os sons da língua em um momento inicial de sua constituição como falante. Trata-se, portanto, do eixo deste trabalho que se situa na linha psicanalítica, com fundamento em autores que abordam as produções sonoras infantis, como é o caso de Didier-Weill (1999), Pommier (2007, 2004), e Porge (2014). Nessa abordagem, a relação inicial do vir-a-ser-falante com os sons da língua é de capital importância para o seu desabrochar futuro como falante, sendo realçada a especial sensibilidade da criança, em sua escuta para esses sons. Sobre tal escuta, lembremos, por exemplo, as aproximações homofônicas entre palavras que se apreendem nas produções verbais infantis, provocando, não raramente, no adulto, um efeito de surpresa; é o caso da aproximação, em virtude de semelhança sonora, entre ver (vê) e verde (vede), na produção de uma criança: Deceu vede que vai ser discutida mais adiante.

Destacam-se, então, os jogos sonoros infantis, também denominados jogos de vocalização ou jogos de ressonância, abrangendo o que Freud (1996 [1907-1908], p. 135) tratou como brincadeiras ou jogos infantis que, segundo ele, consistem em "uma atividade afim à criação literária!". Esse psicanalista afirma então que "A ocupação favorita e mais intensa da criança é o brinquedo ou os jogos" e indaga: "Acaso não poderíamos dizer que ao brincar toda criança se comporta como um escritor criativo [...]?", colocando em seguida: "A linguagem preservou essa relação entre o brincar infantil e a criação poética." (FREUD, 1996 [1907-1908], p. 136).

Assim, destaca-se, também no poeta, uma especial sensibilidade para os sons, o que se torna mais visível em alguns tipos de poema, como é o caso de "Ferreiro" de Andrade (2017, p. 20): "Filho do ferro e da fagulha/ fulgurando na forja formidável/ o seu fole afrouxou e sua força/ em face do fiscal e da folhinha de papel". Nesse poema, o jogo sonoro, pela via da reiteração de fonemas - no caso, a figura denominada aliteração aproxima-se de jogos sonoros infantis, sobretudo pela suspensão do sentido ordinário das palavras. No entanto, segundo Lemos (2006b), uma diferença significativa entre os dois tipos de ludicidade consiste em que, no poema, a suspensão de sentido costura, de forma retroativa, sentidos novos e inusitados, provocando no leitor um efeito estético, o que não ocorre nos jogos sonoros infantis.

\footnotetext{
2 Este artigo resultou da apresentação oral de trabalho no InPLA-2018/PUC-SP - tendo sido feitos acréscimos e modificações - e faz parte da realização de Projeto de Pesquisa financiado pelo CNPq.
} 
No que toca à criança, na linha teórica aqui assumida, os autores referidos no início afirmam que é de capital importância que a criança venha a esquecer/recalcar sua escuta para os sons, a fim de se tornar falante. Desse modo, no eixo da relação lúdica da criança com a língua, o recalque dos jogos sonoros infantis, que daria lugar à emergência da fala propriamente dita ${ }^{3}$, consiste no ponto em torno do qual será tecida nossa discussão. Vale notar, contudo, que se trata de uma tentativa, considerando a complexidade da proposta no âmbito da aquisição de linguagem.

\section{A questão do recalque do som}

Neste momento, faz-se necessário abordarmos a noção de recalque assumida, sem descermos, porém, aos detalhes ou à complexidade nela implicados; serão realçados os aspectos que consideramos relevantes à luz de nosso objetivo.

Iniciamos com a seguinte afirmação:

Ao crescer, as pessoas param de brincar e parecem renunciar ao prazer que obtinham do brincar. Contudo, quem compreende a mente humana sabe que nada é tão difícil para o homem quanto abdicar de um prazer que já experimentou. Na realidade, nunca renunciamos a nada; apenas trocamos uma coisa por outra. (FREUD, 1996 [1907-1908], p. 136).

Essa citação aponta para o recalque - e sua outra face: o retorno do recalcado - em que se destaca "A fórmula segundo a qual a repressão ${ }^{4}$ é um processo que ocorre entre os sistemas Ics. [Inconsciente], Pcs. [Pré-consciente] ou Cs. [Consciente]), resultando em manter-se algo à distância da consciência" (FREUD, 1996 [1915b], p. 207).

Freud (1966 [1915b]) se refere a duas fases do recalque: um recalque primeiro que consiste em negar, ao representante psíquico ideacional da pulsão, a entrada no consciente e um recalque propriamente dito que afeta os derivados mentais do representante recalcado que, por associação, tenham a ele se ligado.

3 Qualificamos, neste momento, o termo fala com a expressão propriamente dita, visando a destacar o fato de que, em estudos de aquisição de linguagem, utiliza-se esse termo em um sentido amplo, abrangendo quaisquer produções verbais infantis, mesmo aquelas que aparecem no início do percurso linguístico em que a criança é, comumente, considerada como um vir-a-ser-falante. Quando fala for, aqui, usada nessa acepção ampla, virá sempre com aspas.

4 Optamos pela tradução do termo alemão Verdrängung por recalque, em português e não por repressão, realçando que os tradutores oscilam entre esses dois termos em suas traduções do texto freudiano. Portanto, somente utilizaremos esse último termo quando se tratar de citação. 
- | Notas sobre a relação lúdica da criança com a língua: a questão do recalque dos sons

Por causa dessa associação, essas ideias sofrem o mesmo destino daquilo que foi primevamente reprimido. [...]; igualmente importante é a atração exercida por aquilo que foi primevamente repelido sobre tudo aquilo com que ele possa estabelecer uma ligação. (FREUD, 1966 [1915b], p. 153)

Nesse sentido, continua: "[...] a repressão não impede que o representante instintual continue a existir no inconsciente, se organize ainda mais, dê origem a derivados, e estabeleça ligações" (FREUD, 1966 [1915b], p. 153)

Assim, o representante pulsional tornado inconsciente não somente continua a existir, como também se submete a um intenso movimento de associação com outros representantes, dando lugar a reorganizações e gerando derivados. Destaca-se, portanto, a extrema mobilidade do recalque, sobre a qual o psicanalista afirma:

O processo de repressão não deve ser encarado como um fato que acontece uma vez, produzindo resultados permanentes, tal como, por exemplo, se mata um ser vivo que, a partir de então, está morto; a repressão exige um dispêndio persistente de força, e se esta viesse a cessar, o êxito da repressão correria perigo, tornando necessário um novo ato de repressão. (FREUD, 1966 [1915b], p. 156, ênfase do autor).

Esse caráter extremamente móbil impede, então, que o recalque ocorra de uma só vez, exigindo uma contínua recondução do recalque (POMMIER, 2004), como também Ihe atribui, como sua outra face, o retorno do recalcado. Quando falamos em recalque de jogos sonoros, não estamos nos referindo, portanto, ao desaparecimento ou apagamento desses jogos, mas a sua permanência, a sua imersão em um incessante movimento de associações que os modifica e os coloca em posição de contínuo retorno. Por sua vez, esse retorno implica diferenças em relação ao que foi recalcado, inferindo-se, então, que o movimento do recalque implica uma reedição dos jogos sonoros em que os mesmos jogos ou jogos semelhantes retornam de tempos em tempos, porém, a cada vez, com novos rearranjos, em virtude de novas associações. Isso nos permite retomar a questão dos jogos sonoros, na criação poética, como um retorno, com diferenças, de jogos sonoros infantis, conforme foi referido antes.

Nessa perspectiva, em relação ao recalque dos sons na criança, recorremos, sobretudo, a Pommier (2007). Segundo esse autor, é a frase - isto é, relações entre significantes, produzindo sentido -, que recalca essa escuta infantil para os sons. Assim, ao falar, o gozo do corpo se metamorfoseia em gozo da palavra; poderíamos dizer que o gozo que a criança encontra nos jogos sonoros transforma-se em gozo na produção 
de frases. Coloca o autor: "À medida que fala, cada um esquece o excesso de ser de seu corpo, ao mesmo tempo em que o excesso de ser das sensações que refletem esse corpo" (POMMIER, 2007, p. 145, tradução nossa) ${ }^{5}$.

Ao conceituar o recalque dos sons, no vir-a-ser-falante, esse autor afirma que "o recalque faz passar a representação de coisa à representação de palavra" (POMMIER, 2007 , p. 152, tradução nossa) ${ }^{6}$, ou seja, da imagem, que pode ter várias fontes pulsionais - acústica, auditiva, sonora, sinestésica -, ao significante. Afirma, a partir da concepção freudiana, que esse recalque funciona como uma barreira, uma contenção, um limite à imagem sonora que não desaparece, mas é transformada em outra representação, assim "como a água gera a eletricidade" (POMMIER, 2007, p. 152, tradução nossa) 7 . Nessa perspectiva, a representação de coisas - isto é, as imagens - é recalcada pela representação de palavras ${ }^{8}$ - os significantes.

Assim, o recalque do som advém da relação entre significantes, relação de diferença, conforme a proposta de Saussure (1916/1989) sobre o valor linguístico. Abrimos um parêntese para lembrar, rapidamente, que, para o fundador da ciência linguística, a língua, como sistema de signos, é uma forma e não uma substância, nela existindo apenas diferenças. Nesse sentido, a língua consiste, a rigor, em um sistema de valores, sendo o valor concebido como uma relação diferencial, opositiva, negativa. O significante e o significado - que se associam formando o signo linguístico ${ }^{9}$ - são, então, definidos por essa relação diferencial, negativa. Em outras palavras, a característica mais exata do significado "é ser o que os outros não são" (SAUSSURE, 1916 [1989], p. 136) o mesmo valendo para o significante.

Realcemos a proposta de que seria por meio da produção de cadeias de significantes, pela criança, que seus jogos sonoros seriam recalcados, fazendo-a então emergir como falante.

\footnotetext{
5 No original: "En parlant, chacun oublie au fur et à mesure le trop d'être de son corps, en même temps que le trop d'être des sensations qui reflètent ce corps".

6 No original: "Le refoulement fait passer la représentation de chose à la représentation de mot".

7 No original: "Comme l'eau donne l'électricité".

8 Para uma visão detalhada da proposta freudiana de representação de coisa e representação de palavra, remetemos a Freud (2013 [1891]) e a Le Gaufey (2018).

9 É importante indicar que, no campo psicanalítico, o signo saussuriano foi colocado em discussão, na leitura lacaniana da proposta freudiana. Não entraremos, porém, nessa discussão; destacamos apenas que, na mencionada leitura, foi fundamental a concepção de significante como diferença. Para um contato com os detalhes da polêmica em torno do signo linguístico, remetemos a Le Gaufey (2018).
} 
- | Notas sobre a relação lúdica da criança com a língua: a questão do recalque dos sons

\section{A passagem de jogos sonoros a cadeias verbais: uma tentativa de abordagem}

Conforme se pode inferir da proposta aqui assumida, a passagem dos jogos sonoros a cadeias verbais não ocorreria de forma repentina ou homogênea, considerando que eles possuem, como marca, a heterogeneidade. A esse respeito, Porge (2014, p. 122) se refere a uma variedade de jogos de vocalização, concebendo o "estádio do eco [que] estaria ligado a este momento de passagem do grito ao apelo e à palavra [...]".

Afirma então: "Entre o grito e [a fala] propriamente dita, há esse tempo de passagem pelo jogo de vocalizações, os balbucios, os gorjeios, as lalações, o motherese ou o parêntese $e^{10}[. .$.$] , em que a criança goza da matéria sonora para seu prazer" (PORGE, 2014,$ p. 120). Para esse autor, "a sonorização é uma imaginarização mais ou menos satisfatória da voz" (PORGE, 2014, p. 109). Convém notar que, nessa perspectiva, os jogos não se restringem ao som, mas podem ser de vários tipos (psíquico, auditivo ou motor), podendo ocorrer simultaneamente e não precisam ser sempre uma repetição estrita.

Pommier (2004, p. 124), por sua vez, afirma: "O diferencial esquece o som". Referese a associações sonoras que recalcam as sensações diretas e coloca: "A associação de um grito a outro qualifica um objeto já diferente daquele das sensações diretas" (PORGE, 2014, p. 142).

Segundo esse autor, o recalque do som se produz segundo dois patamares que regulam sua efetivação. Em suas palavras:

Há, de início, uma espécie de catraca interna no momento da formação de palavras, quando o prazer vocálico encontra um ponto de parada consonantal (ou, mais exatamente, o diferencial que a consoante cava) [...]. É num segundo nível, no momento da realização de uma frase, quando uma palavra se endereça a outra, é que o recalque [do som] se encontra completamente estabelecido. (PORGE, 2014, p. 166-167, tradução nossa) ${ }^{11}$.

Destaca, entretanto, que a palavra isolada - no ato de nomear - ainda consiste em uma entidade sonora, alertando que a associação de palavras, isto é, associação de

10 O termo motherese foi traduzido para o português brasileiro como manhês e o parentese refere-se à fala dirigida ao bebê pelo adulto cuidador ou pelo adulto em geral.

11 No original: "Il existe d'abord une sorte de cliquet interne au moment de la formation des mots, lorsque la jouissance voyellique rencontre le point d'arrêt consonantique (ou plus exactement le différentiel que creuse la consonne). [...] C'est à un deuxième niveau, au moment de l'accomplissement d'une phrase, lorsque la parole s'adresse à un autre, que le refoulement se trouve complètement établi". 
entidades sonoras não constitui uma frase a qual somente é produzida quando uma palavra qualifica, define outra palavra, possuindo como protótipo a cadeia construída com o verbo ser: isto é aquilo.

Nessa perspectiva, repetimos, seria da relação diferencial, relação de oposição entre significantes, na frase, que se efetivaria o recalque dos jogos sonoros infantis. Por sua vez, podemos inferir que esse recalque apontaria para diversas maneiras como os sons seriam associados, ou seja, diversos patamares em que o recalque ocorreria, até se efetivar, completar-se pelo diferencial da cadeia significante.

Nossa tentativa é então a de abordar a relação lúdica da criança com os sons da língua, supondo diferentes maneiras pelas quais os sons são associados nos chamados jogos sonoros infantis, sem a pretensão de reduzir esses jogos aos que serão, aqui, destacados. Por sua vez, essa suposição decorreu de uma escuta anterior (CARVALHO, 2019) da fala de uma criança (pertencente ao Banco de Dados do Projeto de Aquisição de Linguagem do IEL/UNICAMP), com fundamento na proposta teórica exposta.

Convém realçar, porém, que esses jogos sonoros serão abordados e exemplificados, apenas do ponto de vista da diferença entre eles à luz da concepção de recalque do som, segundo Pommier (2007), não se supondo, desse modo, a formulação de fases ou etapas, isto é, não incluindo essas diferenças em um percurso de aquisição de linguagem.
$M=$ mãe
$\mathrm{C}=$ criança
V=avó
$\mathrm{P}=$ pai

(1): C - 1 ano, 2 meses e 1 dia - conversa com sua mãe (M).

(C pega uma revista):

M: Vamo achar uma coisa bonita aqui.

C: u auau

[...]

V: (para M) Quem é esse aqui? Que que o nenê tá fazendo? Olha.

C: mamá

M: Mamá? Tá mamando? Cadê o au au da M?

C: uáuá (apontando)

[...]

M: Essa aí é a moça

C: uá nenê

M: Au au nenê? 
- | Notas sobre a relação lúdica da criança com a língua: a questão do recalque dos sons

C: naná

M: Este aqui que você quer?

C: é não

M: Não? (ri)

V: Num é esse não, bem?

M: Qual que é? É este aqui que tá mamando?

C: mamá mamá/uauá

M: Au au.

C: uaúa Tetê papa

(2): $\mathrm{C}-1$ ano, 3 meses e 26 dias:

C: Au au au

M: O au au está aqui na frente.

C: É dei ié

M: E esse. O pato está conversando com o au au. E aqui, com que que o pato está conversando?

$\mathrm{C}: \mathrm{Au} / \mathrm{iau}$

Nesses episódios, podemos apreender a presença de entidades sonoras tanto constituídas por sons vocálicos (uáuá, auau, au/iau, uaúa, uá) nos episódios 1 e 2, como por sons vocálicos e consonantais, como mamá, naná no episódio 1, exemplificando uma barreira a esse fluxo sonoro, a fim de transformá-lo em sequências sonoras com contornos mais definidos de acordo com termos da língua.

Remetemo-nos, então, à proposta de Pommier (2011) sobre o lugar que a vogal ocupa em um momento inicial da "fala" e escrita infantis. Esse autor se refere a "fluxo vocálico" (POMMIER, 2011, p. 72) que podemos ler como uma continuidade sonora, ou melhor, a materialização da continuidade da música materna, fluxo que é detido pela introdução da consoante que promove o corte, a interrupção dessa continuidade. Diz o autor: "Elas [as vogais] constituem o magma sonoro aberto; recortado e organizado pelas consoantes. [...] Essa relação com a pulsão situa as vogais como 'letras maternas', que as consoantes (escrita da lei) organizam progressivamente no momento do acesso à linguagem" (POMMIER, 2011, p. 72).

(3): C - 2 anos e vinte e nove dias - está conversando com a mãe (M) e dando pipoca ao cachorro (uma figura na revista):

M - É do cachorro? 
C - É é/paqui/paqui/é cossa mais

Ta cumendu qui com (quase sem som)

Num com cómissó vagazinho

M - Ah! Come divagarzinho.

C - toma í toma í comi/cói/cói

cómi vazinhu cómi mais cómi

comi come ta comendu u cachoínhu

cómi/cómi/ta cumendu

dexu fazê mais (quase sem som)

(4): C - 2 anos 1 mês e doze dias - está brincando de amamentar um boneco (cebolinha):

$\mathrm{C}$ - Eu tenhu/ ũ/ bastanti petu

$M-A h$ ! Você põe no seu peito?

$\mathrm{C}$ - Tem sigula essi matalu

é tila (Põe o boneco para mamar no seu peito)

ahn/ cebolinha ahn mama mama

aqui mama aqui tá mamando

mamô ele mamô/ mãe

Convém notar que, em alguns momentos, a criança começa nomeando com uma palavra (ou entidade sonora) um objeto ou uma situação, por exemplo, em uma revista, para, em seguida, colocar essa palavra em um fluxo associativo com outras palavras. Convocando Lemos (2006a), diríamos que a criança, de início, está imersa em uma cena a cena de nomeação de objetos ou figuras - saindo dessa cena, por meio das associações entre palavras. Ao discutir um episódio de diálogo entre uma criança e sua mãe onde se reconhece, na fala infantil, fragmentos da fala do outro (a mãe), essa autora afirma:

As relações entre constituintes do enunciado precedente da mãe e constituintes de textos dirigidos à criança em situações anteriores, que se depreendem no segundo enunciado da criança, dão-se intratextos. Melhor dizendo, não se apoiam em situações externas, não se dão entre cenas, como é o caso do primeiro enunciado. Essas relações que são internas a textos podem ser responsáveis pela obliteração ${ }^{12}$ das situações externas desencadeadoras desses textos. (LEMOS, 2006a, p. 29).

12 Em outro momento, Lemos (2014) usa o termo recalque - no sentido psicanalítico - em vez de obliteração. 
- | Notas sobre a relação lúdica da criança com a língua: a questão do recalque dos sons

Essa citação fundamenta a substituição que farei do termo obliteração por recalque (com sua outra face: o retorno do recalcado). Assim, a associação de palavras seria a responsável pelo recalque da nomeação, isto é, da ligação entre um nome e uma cena referencial.

Nos episódios 3 e 4, deve-se notar que se trata de uma "associação de palavras", para destacar, segundo Pommier (2007), que não haveria, nessa produção infantil, a qualificação ou definição de uma palavra por outra, não se tratando, portanto, de uma relação diferencial que caracteriza o significante, ou seja, não se tratando de uma frase que produz sentido. Nesse fluxo associativo, uma palavra desliza para outras palavras, percorrendo, às vezes, um longo caminho e deixando visível a diferença no tocante à produção infantil de palavra isolada.

Embora, como foi dito antes, não seja nossa pretensão relacionar esta abordagem dos jogos sonoros infantis à questão da trajetória do infans em sua constituição como falante, é importante notar que os episódios mostrados, até agora, constituem exemplos do que Lemos (2002) concebeu como espelhamento. Diríamos que se trata de um espelho sonoro (PORGE, 2014); assim, fragmentos sonoros de enunciados do outro (mãe) migram para a fala infantil. Esses fragmentos, contudo, movimentam-se, isto é, sofrem modificações, sendo essas modificações guiadas, sobretudo, pela semelhança de som, de ritmo, de acento. Podemos dizer, a partir da noção de eco (em PORGE, 2014), que a fala da criança ecoa a fala da mãe ${ }^{13}$ e vice-versa, ocorrendo ecos também no interior da fala infantil, através de um movimento de associações e permutas.

(5): C - 2 anos, e 8 dias - está pronta para ir ao aniversário de um amiguinho:

M: Da onde é essa chave?

C: Fom fom

M: Do carro? Bonito esse chaveiro da K verde.

C: Deceu vede/ esse num é/ esse/ maon

M: Esse é marrom?

C: É

M: Não, é verde. Abre a boca prá tomar remédio.

13 Convém notar que Pereira de Castro (2006) destaca na chamada língua materna sua impossibilidade de ser esquecida. 
Nesse episódio, podemos supor que não existiria ainda uma frase, ou seja, uma palavra que qualifica ou define outra palavra, uma vez que escutamos, no termo equívoco vede, uma associação sonora entre ver e verde que produz um amálgama entre eles, não nos permitindo decidir com segurança de qual dessas duas palavras se trata, mesmo tendo a criança produzido, em seguida, esse/maon. Supomos, então, que estamos ainda diante de uma entidade sonora, segundo a proposta assumida.

Podemos, entretanto, supor que o amálgama entre ver e verde estaria indicando um lugar cavado na entidade sonora Deceu $X$, mostrando que esse jogo se distingue do anteriormente exemplificado (episódios 3 e 4) onde ocorreu a mera associação de entidades sonoras.

Em relação à escavação desse lugar, remeto aos jogos sonoros investigados por Lier-De Vitto (2006 e outros), em seus estudos sobre as produções infantis paralelísticas, nas quais as diferenças sonoras aparecem como parte do mesmo som. Essa autora afirma que, nos casos de paralelismo (que ela estudou nos chamados monólogos no berço), procurou "dar relevo à jogada sonora que se impõe à fala da criança", distinguindo "o jogo de composição/decomposição/recomposição da substância sonora" (LIER-DE VITTO, 2006, p. 122).

Indagamos se esses jogos não estariam indicando uma contenção, um limite ao fluxo associativo de palavras na fala infantil.

Ao que parece, contudo, em outras produções de C, o diferencial do significante, ou seja, a qualificação ou definição de uma palavra por outra estaria predominando, como no episódio que se segue:

(6): C - 2 anos, 10 meses e 14 dias

C: Eu tô/eu só ladão/ela/essa éladinha/i eu vô/vô/fala ladão/i eu sô u ladão i ele éu ladinho M: Ladinho!

P: Ladinho é a tua vó!

Num existe ladinho.

M: É um ladrão pequenininho.

Como se pode notar, teria havido nas produções de C, nesse episódio, uma predominância da cadeia, da relação diferencial entre os termos - uma palavra qualifica outra -, destacando-se também a dimensão morfológica da língua. Assim, a cadeia ela éX teria determinado a transformação do termo ladão (ladrão) - que aparece na cadeia 
- | Notas sobre a relação lúdica da criança com a língua: a questão do recalque dos sons

anterior: Eu só ladão - para o feminino (ladinha), com a terminação $a$, já que se refere a ela/ essa. No entanto, nessa transformação, teria havido a interferência do segmento (sonoro) final ão (de ladão) que, embora, na língua portuguesa, corresponda a um sufixo indicador do grau aumentativo, não se trata desse sufixo, no caso de ladrão. Essa interferência fez com que a menina transformasse ladão em ladinha na cadeia Ela é X e em ladinho, na cadeia Ele é $X$. Desse modo, admitimos que a semelhança sonora teria aproximado ladrão de outros termos como meninão (menininho/menininha), em virtude da terminação sonora ão. No que diz respeito a esse tipo de produção verbal infantil, remeto à análise e discussão realizadas por Rosa Figueira (2005), tomando como eixo a noção saussuriana de analogia. O que podemos dizer é que, nessa predominância da cadeia verbal e de efeitos gramaticais, uma escuta para o som teria escapado ao recalque produzido pelo diferencial do significante. Por sua vez, o efeito que a produção infantil provoca, no outro, seria o de um erro gramatical, o que indica a afirmação de P: Num existe ladinho.

\section{Considerações finais}

A discussão dos episódios exemplificados, ao que parece, pôde indicar a complexidade implicada na questão da passagem de jogos sonoros a cadeias de significantes, na "fala" infantil, a partir da proposta de que o recalque funciona como operador em tal passagem. Lembremos que se trata de uma tentativa de abordar esse operador, ou seja, uma tentativa de abordar os patamares em que ele atua durante a constituição da fala, sem se perder de vista as dificuldades que marcam a proposta.

Com base no que foi posto, indagamos: não estaríamos diante de uma diversidade de patamares, em relação ao recalque do som no vir-a-ser-falante? Poderíamos falar em patamares $^{14}$, já que esse termo implica certa separação entre um patamar e outro? A coexistência - ou mesmo a imbricação - de patamares, em produções sonoras infantis não estaria apontando para a heterogeneidade que marca essas produções?

Talvez pudéssemos falar em modos de atuação do recalque ou modos de apagamento que, segundo a proposta lacaniana, consistem na "dissolução desse laço que remetia o signo à coisa que ele estava encarregado de representar [e] é a condição do surgimento de um significante como tal'15 (LE GAUFEY, 2018, p. 214, ênfase do autor)

\footnotetext{
14 Patamaré a tradução para o português brasileiro do termo francês palier usado por Pommier (2007). Segundo o Dicionário de Houaiss (2001, p. 2147), Patamar significa "área plana e relativamente ampla, localizada no alto ou entre dois lanços de uma escada".)

15 Na proposta lacaniana, o signo é concebido como aquilo que representa alguma coisa para alguém. Tratase, portanto, de uma concepção diferente da de Saussure (1916/1989) que denomina signo a associação entre o conceito (o significado) e a imagem acústica (o significante).
} 
Le Gaufey (2018) destaca que, nessa proposta, quando traços mnésicos se associam, rompe-se a ligação entre o traço isolado e o seu referente; em virtude dessa ruptura, o sentido é, momentaneamente, suspenso, fazendo emergir os significantes que se relacionam entre si. Existem, assim, diversos apagamodos ${ }^{16}$, isto é, modos de surgimento do significante e, portanto, de manifestação do sujeito. No caso do vir-a-ser-falante, diríamos que seriam modos pelos quais a criança se manifesta em sua constituição como sujeito/falante.

Antes de finalizar, pareceu-nos importante destacar, embora rapidamente, o lugar fundamental ocupado pelo outro (a mãe) nessa proposta. Assim, os autores, na linha psicanalítica, referidos neste artigo, realçam tanto o endereçamento dos jogos sonoros ao outro (no caso, a mãe), como o retorno do outro, por meio de um enunciado dirigido à criança, enunciado que inclui, de algum modo, esses jogos. Abro um parêntese para indicar o alerta desses autores de que o outro pode se fazer presente "de forma real ou fictícia" (POMMIER, 2007, p. 155). Quanto à escuta da mãe para esses jogos em seu retorno através de enunciados dirigidos à criança, convém notar a concepção de Vivès (2016) do que ele chama de improviso materno, improviso no sentido de execução musical. Nessa perspectiva, o improviso respeita tanto as regras musicais, quanto as características da música a ser executada, deixando, porém, um lugar para a marca da subjetividade daquele que improvisa. No caso da interpretação da mãe, os seus enunciados respeitam tanto as leis da língua, como as características dos jogos sonoros da criança.

Quanto à marca subjetiva do improvisador materno, propomos que ela se constituiria como efeitos provocados, em seu corpo, pelos jogos sonoros infantis; em outras palavras, a escuta da mãe para esses sons faria retornar, nela, jogos sonoros já recalcados, imprimindo uma singularidade em sua improvisação.

Propomos que também o investigador, embora em outra posição, sofreria os efeitos desse retorno do recalcado, com fundamento em Lemos, M. (2002), ao conceituar o efeito de estranhamento produzido, nesse sujeito, pelas produções insólitas da criança, com fundamento na concepção freudiana de estranho familiar. Assim, a escuta de combinações inusitadas de significantes nas produções infantis faria retornar, no investigador da aquisição de linguagem, esse tipo de combinações já recalcadas, provocando um efeito de estranhamento ou efeito de enigma.

Indagamos, por fim, se os jogos sonoros infantis escutados pelo investigador não afetariam seu corpo, fazendo retornar jogos sonoros já recalcados, provocando, então,

16 O termo Apagamodos é a tradução, para o português brasileiro, do termo francês effaçons que consiste em um neologismo lacaniano. Essa tradução se encontra em Le Gaufey (2018). 
- | Notas sobre a relação lúdica da criança com a língua: a questão do recalque dos sons

efeito de estranhamento/de surpresa/de encantamento que o leva a imprimir sua marca na escuta para esses jogos.

Para encerrar este artigo, transcrevemos o seguinte poema de Manoel de Barros (2010, p. 301):

No descomeço era o verbo.

Só depois é que veio o delírio do verbo.

O delírio do verbo estava no começo, lá onde a criança diz: eu escuto a cor dos passarinhos.

A criança não sabe que o verbo escutar não funciona para cor, mas para som.

Então se a criança mudar a função de um verbo, ele delira.

E pois.

Em poesia que é voz de poeta, que é a voz de fazer nascimentos - o verbo tem que pegar delírios.

\section{Referências}

ANDRADE, C. D. Boitempo: esquecer para lembrar. São Paulo: Companhia das Letras, 2017 [1979].

BARROS, M. O livro das ignorãças. In: BARROS, M. Poesia Completa. São Paulo: Leya, 2010 [1993].

CARVALHO, G. M. M. Jogos sonoros na fala infantil e mudanças na interpretação do outro. Lingüística, v. 35, n. 2, p. 75-84, 2019.

DIDIER-WEILL, A. Invocações: Dionísio, Moisés, São Paulo e Freud. Rio de Janeiro: Companhia de Freud, 1999.

FIGUEIRA, R. A. A Criança na língua: erros de gênero como marcas de subjetivação. Cadernos de Estudos Linguísticos, Campinas, n. 47, p. 29-47, 2005.

FREUD, S. Sobre a concepção das afasias: um estudo crítico. Belo Horizonte: Autêntica, 2013 [1891]. 
FREUD, S. Escritores criativos e devaneios. In: Edição Standard das Obras Completas de Sigmund Freud. Tradução Jayme Salomão. v. IX. Rio de Janeiro: Imago, 1996 [1907-1908]. p. 131-143.

FREUD, S. O inconsciente. In: Edição Standard das Obras Completas de Sigmund Freud. Tradução Jayme Salomão. v. XIV. Rio de Janeiro: Imago, 1996 [1915a]. p. 163-222.

FREUD, S. Os instintos e suas vicissitudes. In: Edição Standard das Obras Completas de Sigmund Freud. Tradução Jayme Salomão. v. XIV. Rio de Janeiro: Imago, 1966 [1915b]. p. 115-144.

HOUAISS, A. Dicionário Houaiss de sinônimos e antônimos. Rio de Janeiro: Objetiva, 2001.

LE GAUFEY, G. A incompletude do simbólico: de René Descartes a Jacques Lacan. Tradução Paulo Sérgio de Souza Júnior. Campinas: Editora UNICAMP, 2018.

LEMOS, C. T. G. A criança e o linguista: modos de habitar a língua? Estudos Linguísticos, São Paulo, n. 43, v. 2, p. 954-964, 2014.

LEMOS, C. T. G. Uma crítica (radical) à noção de desenvolvimento na Aquisição da Linguagem. In: LIER- DE VITTO, M. F.; ARANTES, L. (org.). Aquisição, Patologia e Clínica de Linguagem. São Paulo: EDUC/FAPESP, 2006a. p. 21-32.

LEMOS, C. T. G. Sobre o paralelismo, sua extensão e disparidade de seus efeitos. In: LIERDE VITTO, M. F.; ARANTES, L. (org.). Aquisição, Patologia e Clínica de Linguagem. São Paulo: EDUC/FAPESP, 2006b. p. 97-107.

LEMOS, C. T. G. Das vicissitudes da fala da criança e de sua investigação. Cadernos de Estudos Lingüísticos, Campinas, n. 42, p. 41-69, 2002.

LEMOS, M. T. G. A língua que me falta: uma análise dos estudos em aquisição da linguagem. São Paulo: Mercado de Letras, 2002.

LIER-DE VITTO, M. F. "Delírios da língua": o sentido linguístico (e subjetivo) dos monólogos da criança. In: LIER- DE VITTO, M. F.; ARANTES, L. (org.). Aquisição, Patologia e Clínica de Linguagem. São Paulo: EDUC/FAPESP, 2006. p. 79-95. 
- | Notas sobre a relação lúdica da criança com a língua: a questão do recalque dos sons

PEREIRA DE CASTRO, M. F. Sobre o (im)possível esquecimento da língua materna. In: LIERDE VITTO, M. F.; ARANTES, L. (org.). Aquisição, Patologia e Clínica de Linguagem. São Paulo: EDUC/FAPESP, 2006. p. 135-148.

POMMIER, G. Da passagem literal do objeto ao moedor do significante. In: MELMAN, C. et al. (org.). O significante, a letra e o objeto. Tradução Procopio Abreu. Rio de Janeiro: Companhia de Freud, 2004. p. 119-126.

POMMIER, G. Comment les neurosciences démontrent la Psychanalyse. Paris: Champs/ Flammarion, 2007.

POMMIER, G. Problemas clínicos da escrita. In: LIER-DE VITTO, M. F.; ARANTES, L. Faces da escrita: linguagem, clínica, escola. Campinas: Mercado de Letras, 2011. p. 53-74.

PORGE, E. Voz do eco. Tradução Viviane Veras. Campinas: Mercado de Letras, 2014.

SAUSSURE, F. Curso de linguística Geral. Tradução Antônio Cheline, Paulo Paes e Izidoro Blikstein. São Paulo: Editora Cultrix, 1916 [1989].

VIVÉS, J-M. A improvisação materna. Biblioteca Virtual do Instituto Vox de Pesquisa em Psicanálise. São Paulo, 2016. Disponível em: voxinstituto.com.br/wp-content/ uploads/.../j-m-vives-a-improvisacao-materna_10.pdf. Acesso em: 20 nov. 2018.

COMO CITAR ESTE ARTIGO: CARVALHO, Glória Maria Monteiro de. Notas sobre a relação lúdica da criança com a língua: a questão do recalque dos sons. Revista do GEL, v. 16, n. 3, p. 111-126, 2019. Disponível em: https://revistadogel. gel.org.br/ DOI: http://dx.doi.org/10.21165/gel.v16i3.2747

Submetido em: 12/10/2019 | Aceito em: 05/12/2019. 